\title{
Acute care model of addiction treatment not enough for substance abuse
}

\author{
Cite as: CMAJ 2018 October 22;190:E1268-9. doi: 10.1503/cmaj.109-5668
}

Posted on cmajnews.com on Oct. 4, 2018.

anada needs to flip its approach to addiction recovery if it hopes to curb overdose deaths, according to experts at the Recovery Capital Conference of Canada, held recently in Toronto.

Despite understanding addiction as a chronic yet curable condition, "we seem to be culturally stuck in this acute care paradigm," said Dr. John Kelly, an associate professor of psychiatry in addiction medicine at Harvard University. Under this acute model, the focus is keeping people alive long enough to be diagnosed, stabilized and discharged. Like firefighters, "we put out the fire - job done," Kelly said. "We haven't thought very much about how to prevent the fire from restarting or providing rebuilding materials."

According to Dr. Julian Somers, a professor of health sciences at Simon Fraser University, this approach has been costly and ineffective. People who don't get better despite repeated bouts of treatment ping pong between health care and the justice system or end up dead. Medication is the most common treatment for addiction but works only if people take it, and many don't take it consistently.

Most of the people with substance abuse problems who recover do so on their own, noted Somers. Access to social supports, not treatment, is the main difference between those who get better and those who don't, he explained.

These preconditions for change, known as recovery capital, include external supports like close relationships, stable employment and housing, but also internal strengths like coping skills and faith. People with less recovery capital have fewer resources or reasons to recover, despite repeated attempts, Somers said.

This helps to explain why addiction and overdose deaths in the United States are concentrated in areas that have gone through economic and social upheaval. It also explains why clinical treatment alone can't address addiction.

Somers and colleagues' study of people with substance problems living on the streets of Vancouver found they had numerous contacts with the health and justice systems in the previous year, yet still had unaddressed needs. Treating addiction episodically and leaving people to rebuild their lives alone may be putting the cart before the horse. Housing-first initiatives show how flipping that model delivers better outcomes, according to Somers.

Housing people with substance problems increased their adherence to medications and reduced emergency visits and reoffences, found Somers and colleagues' study. By contrast, few people who received conventional care got off the streets. "Their exposure to this revolving door of services was like picking a scab off a constantly open psychological wound," said Somers.

Part of the reason why it's so difficult to kick addiction is that the brain becomes more sensitive to stress and less able to experience reward. According to Kelly,

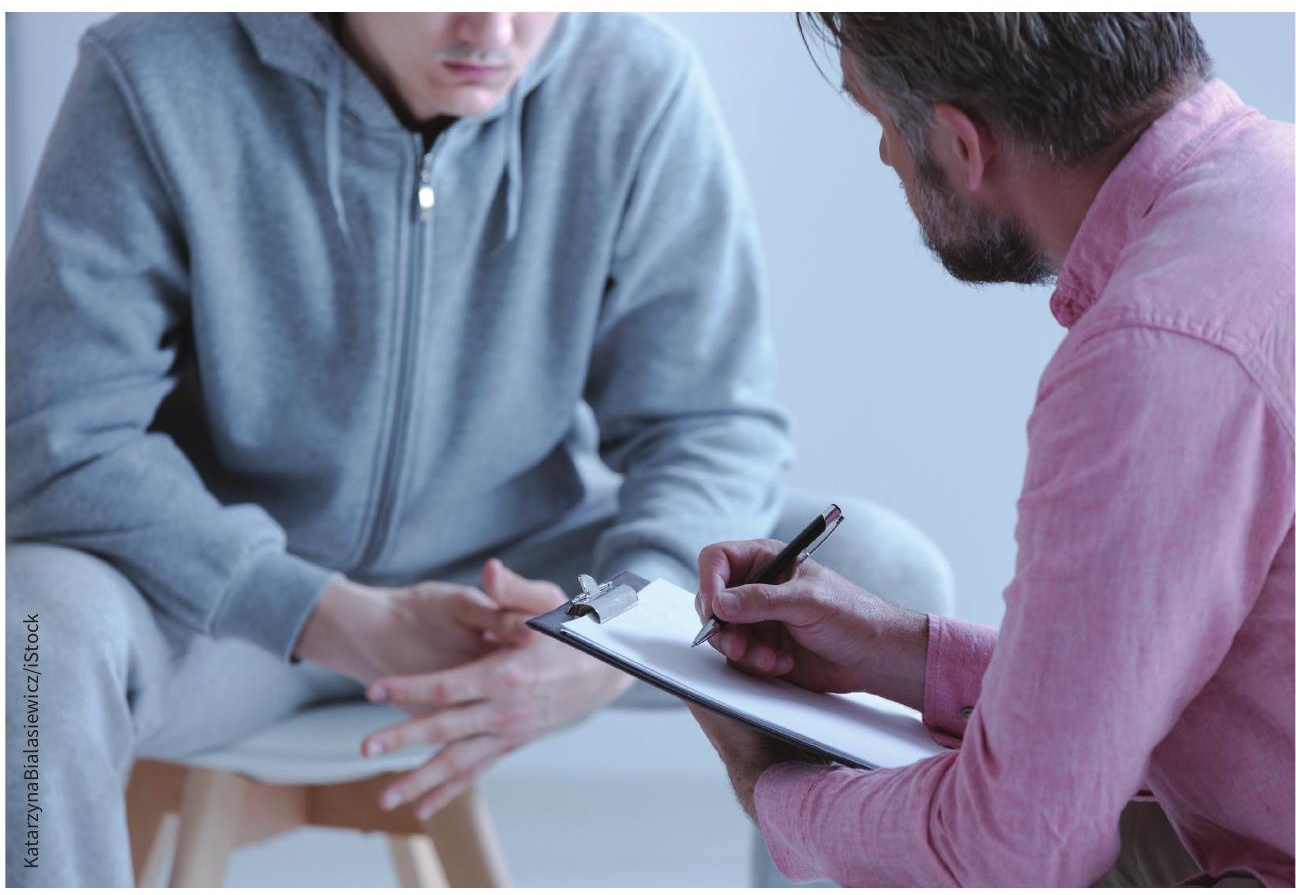

Clinical treatment for addiction may be a pathway to recovery but too often it's treated as the end of the line. 
higher levels of social status and support can buffer stress and have been linked to an increase in ability to experience reward.

"It suggests that social environment and access to resources can change not just the psychosocial outlook, but there are probably neurobiological changes going on under the hood that are protective against relapse," said Kelly.
There are already community models for providing long-term recovery support, from 12-step groups and recovery coaches, to sober houses and recovery high schools. These tend to be less costly than clinical treatment and, in the case of 12-step groups, achieve higher rates of full or partial remission than professional therapy.
However, turf battles between community and addiction services have hampered the integration of some of these models into a broader system focused on recovery, said Kelly. "We need to champion this notion of recovery by any and all means possible."

Lauren Vogel, CMAJ 